\title{
A collaborative approach to investigate site fidelity, home range, and homing behavior of cabezon (Scorpaenichthys marmoratus)
}

\author{
Carlos Mireles , Royden Nakamura, Dean E. Wendt
}

\begin{abstract}
A B S T R A C T
Understanding the area use requirements of species targeted for protection by marine protected areas (MPAs) is critical to the future conservation efforts of economically important fish species. Knowledge of home range size and site fidelity is essential in determining whether species will benefit from the protection offered by a MPA, the size of the area needed to protect individuals, and the extent to which surrounding unprotected areas may be supplemented through post-recruitment movement or "spillover". We utilized a traditional mark and recapture approach, along with GIS spatial analysis to investigate the site fidelity, home range, and homing behavior of the economically important fish species cabezon (Scorpaenichthys marmoratus) on the south central coast of California. In collaboration with members of the commercial live-fish fishery, a total of 1240 sub-adult and adult cabezon were tagged during 10 days of fishing from September to December of 2004 along $18 \mathrm{~km}$ of coastline. A public awareness and reward program resulted in 330 total recaptures from 290 different individuals (23\% recapture rate) with recaptured individuals at liberty up to 1000 days after initial tagging. A majority of individuals displayed high site fidelity, with $81 \%$ of recapture events occurring within $100 \mathrm{~m}$ of their initial capture locations, and only 9 individuals $(.03 \%)$ recaptured greater than $1 \mathrm{~km}$. Most individuals $(64 \%)$ displayed home ranges less than $1000 \mathrm{~m}^{2}$. Ten individuals recaptured after experiencing translocation of up to $5.3 \mathrm{~km}$ displayed strong homing behavior, returning to within $14 \mathrm{~m}$ of their initial capture locations. Findings suggest that under circumstances where suitable habitat is available in nearby unprotected areas, that adult "spillover" will likely be limited to areas within $100 \mathrm{~m}$ from MPA boundaries. In addition, the size of the area needed to protect individual cabezon, should be at least $1000 \mathrm{~m}^{2}$. Findings from this study demonstrate many of the potential benefits of scientists and fishers working together to investigate area use patterns of economically important fish species to facilitate future design and assessment of MPAs.
\end{abstract}

\section{Introduction}

Marine protected areas (MPAs) are being increasingly utilized as a tool for marine conservation and to aid in supporting sustainable fisheries. In California, knowledge related to the role that MPAs play as a fisheries conservation tool has been brought to the forefront with the adoption of the California Marine Life Protection Act (MLPA) in 1999. This act calls for a network of MPAs extending along the entire California coastline to be created by the end of 2011 . Although the overall goals of the MLPA are to promote the natural functioning of the ecosystem as a whole, it has been suggested that networks of MPAs also have the potential to benefit fisheries (Gell and Roberts, 2003; Roberts et al., 2005; Abesamis and Russ, 2005; Gaines et al., 2010). The increased growth and production within
MPAs has been reported to benefit surrounding fisheries through the enhanced export of eggs and larvae to surrounding fished areas, as well as the movement (spillover) of juvenile-adult stages of individuals to surrounding unprotected areas (Kramer and Chapman, 1999). In order to determine the extent to which a species and their associated fisheries may benefit from MPAs, knowledge of species home ranges (area normally used by individuals), as well as their fidelity to these ranges is needed (Kramer and Chapman, 1999).

Cabezon (Scorpaenichthys marmoratus) (Cottidae) is an economically important nearshore reef fish species that has been suggested to directly benefit from the protection offered by MPAs (CA DFG, 2008). Cabezon range from Pt Abreojos, in Baja California, to Sitka, Alaska, and individuals attain the largest sizes of any species in the Cottidae family (max total length (TL) $99 \mathrm{~cm}$ ) (Miller and Lea, 1972). Historically, cabezon was of minor commercial importance (O'Connell, 1953), until the establishment of the nearshore live-fish fishery in Los Angeles, California in the late 1980s (WilsonVandenburg and Hardy, 2001). Findings from a recent tagging study, found the average size of cabezon residing within an 


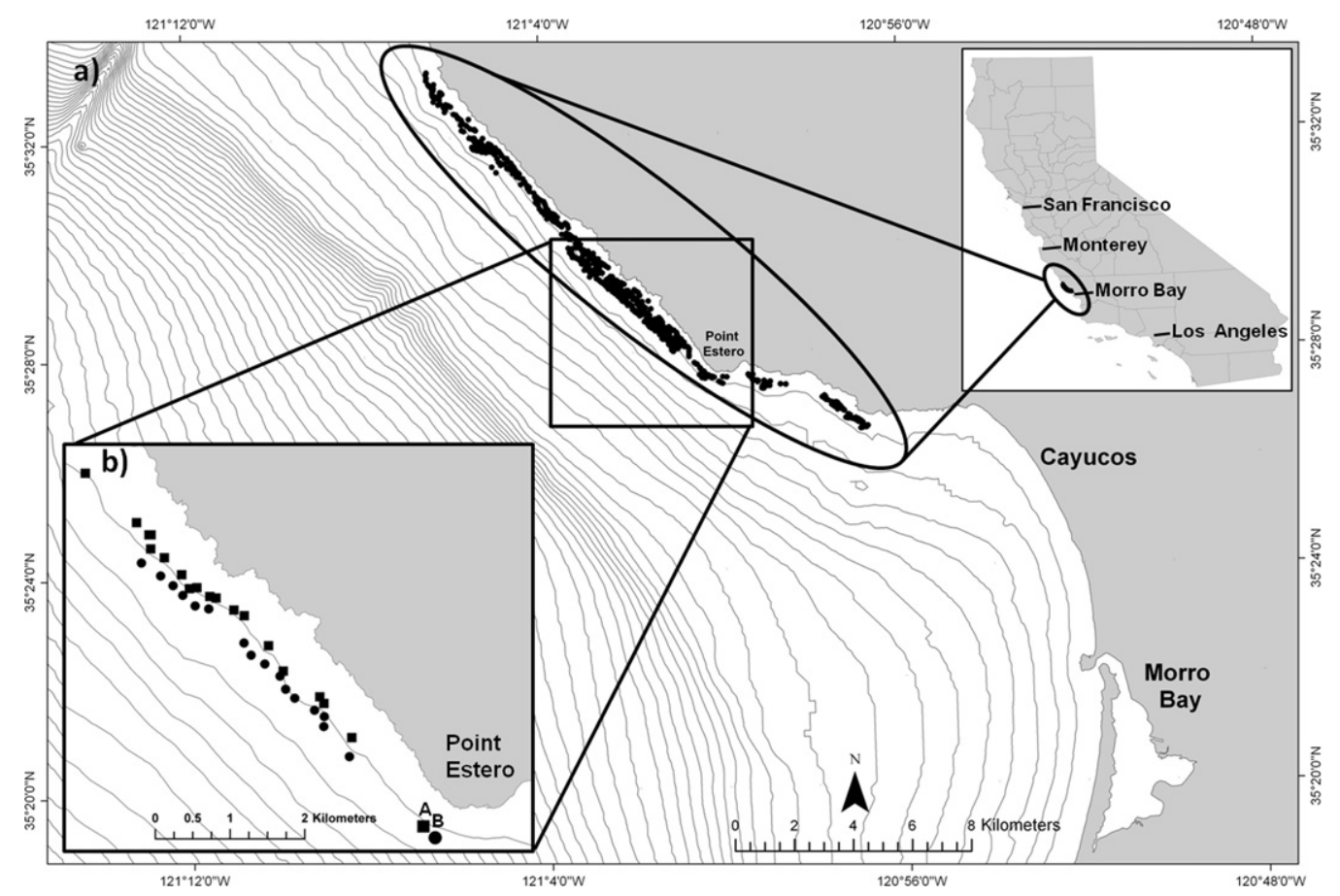

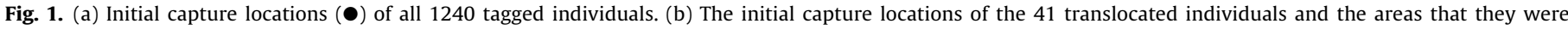

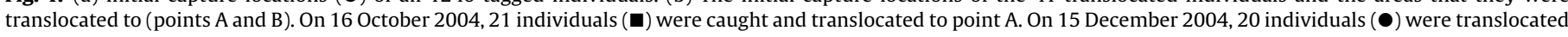
to point $\mathrm{B}$. Bathymetry lines represent $10 \mathrm{~m}$ isobaths.

established MPA (Big Creek Marine Reserve, est. 1993), to be significantly larger than individuals residing within unprotected areas (Rasmussen, MSc Thesis, 2010), suggesting that cabezon may benefit from the protection offered by MPAs.

Little is known about the site fidelity of cabezon. A previous mark and recapture study reported that 3 recaptured cabezon that were at liberty from 18 to 54 days "exhibited no movement" from their initial capture site (Lea et al., 1999). An acoustic monitoring study found cabezon inhabiting petroleum platforms in the Santa Barbara Channel to display site fidelity to platforms for up to 560 days (Lowe et al., 2009). Previous dive surveys described cabezon to change their depths "little if at all" between diurnal periods (Ebeling and Bray, 1976). Although previous studies suggest that cabezon individuals display limited movement, their home range has not been documented. If cabezon display high degrees of site fidelity to certain areas, an understanding of homing behavior (ability of individuals to return to home ranges after displacement) can provide further insight into the importance of these home areas to individuals. Other Cottids such as woolly sculpin (Clinocottus analis) (Williams, 1957) and tidepool sculpin (Oligocottus maculosus) (Green, 1971; Khoo, 1974) have been found to display homing behavior to the tide pools from which they were displaced, suggesting that species within this family show high site fidelity to a particular area. The ability of cabezon to display homing behavior is supported by a report of one translocated individual being recaptured in the vicinity of its initial capture location (Lea et al., 1999), although the distance of translocation and recapture proximity to initial capture location was not reported for the individual. Considering that the home range and site fidelity of some fish species have been found to be dependent on various life history characteristics such as size (Larson, 1980; Nanami and Yamada, 2008) and sex (Kerwath et al., 2007; Afonso et al., 2008), an understanding of how these factors may influence the home range and site fidelity of cabezon is also critical in the design of MPAs and for future fishery management strategies.
The goal of this research was to assess the site fidelity, home range, and homing behavior of cabezon on the south central coast of California using a geographical information system (GIS), prior to the establishment of the MLPA. A traditional mark and recapture approach was used in collaboration with local commercial fishers participating in the nearshore live-fish fishery based out of Morro Bay, CA, a port reported to contribute most out of all California ports to the live-fish fishery catch in the 2005 stock assessment of cabezon (Cope and Punt, 2005). This collaboration provided a broader pool of knowledge and expertise to meet research objectives (Wendt and Starr, 2009). By participating in the scientific process, fishers were able to gain a stronger understanding of research findings, which has been found to result in reduced resource conflicts (Pomeroy et al., 2007). Prior to this investigation, the site fidelity and home range requirements of cabezon and how these factors related to life history characteristics were not known. The objectives of this study were to (1) determine the site fidelity of individuals related to size, sex, and depth of capture, (2) estimate the home range of cabezon related to the size, sex, and days at liberty, (3) determine the homing capability of cabezon after displacement, and (4) discuss the findings in context of future monitoring and assessment of MPAs as fisheries conservation tools.

\section{Materials and methods}

\subsection{Study area and tagging}

The study area for this investigation extended approximately $18 \mathrm{~km}$ along the coastline of south central California, with the southernmost sampling location at Killers Reef in Cayucos, extending northward to Leffingwell Landing in Cambria (Fig. 1a). Tagging began on 4 September 2004 and concluded on 12 December 2004. Two fully outfitted commercial fishing vessels based out of Morro Bay Harbor were used in this study, the 42 foot F/V Kathryn $\mathrm{H}$ (owned and operated by Tom Hafer) and the 24 foot F/V Dorado (owned and operated by Roger Cullen). The sampling regime 


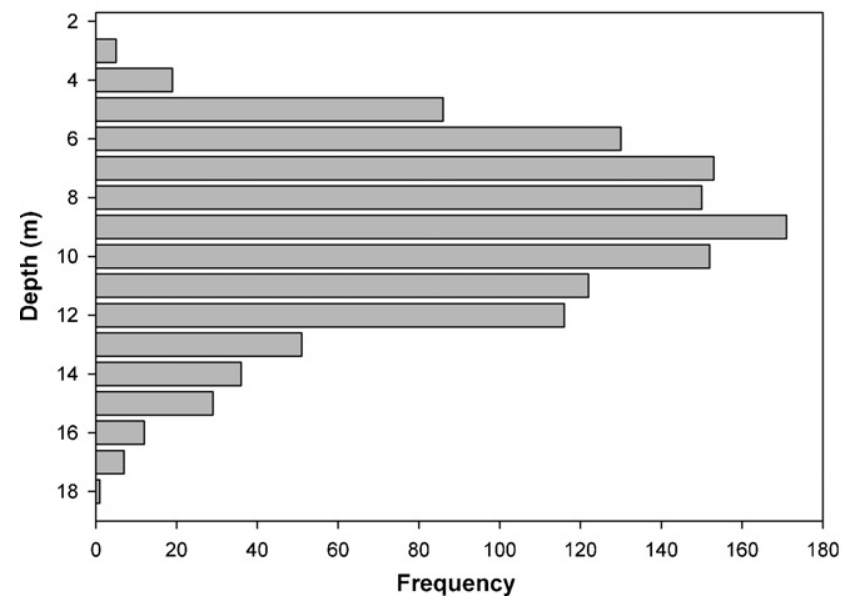

Fig. 2. Frequency of individuals initially captured and tagged by depth.

involved 10 full-sampling or fishing days (5 days each vessel) distributed over 102 total days.

Sampling occurred at depths ranging from 2.7 to $18.3 \mathrm{~m}$ (Fig. 2), with the habitat in this area characterized by semi continuous rocky reef with patchy kelp cover. While the dimensions of the live traps were not identical on both vessels, they were similar in operation (Kathryn $\mathrm{H}=61 \mathrm{~cm} \times 61 \mathrm{~cm} \times 25 \mathrm{~cm}$; Dorado $=46 \mathrm{~cm} \times 61 \mathrm{~cm} \times 20 \mathrm{~cm}$ ). Three sets of forty-four individually identifiable traps were set during each day's fishing effort. The first set was placed in the morning (06:00-09:00), the second in the mid-morning (09:00-12:00), and the third in the afternoon (12:00-15:00). The first 8 days of fishing targeted new areas within the study area, while days 9 and 10 were used to resample previously fished areas. The fishing effort on the larger F/V Kathryn $\mathrm{H}$ generally targeted deeper portions of reefs (mean depth $( \pm \mathrm{SD})=10.3 \pm 2.4 \mathrm{~m})$ and trips on the smaller $\mathrm{F} / \mathrm{V}$ Dorado targeted shallower areas (mean depth $( \pm \mathrm{SD})=7.4 \pm 2.0 \mathrm{~m})$ that were at times only accessible during certain tidal conditions. Once we defined the area to be fished during each day, fishers were asked to fish as they would during their normal fishing effort. Each trap was soaked for approximately $90 \mathrm{~min}$. Once retrieved, traps were rebaited with squid and processed abalone trimmings and re-set. This standardized multiple sampling protocol was necessary to acquire traditional fishery statistics not reported in this paper (i.e. CPUE, population size).

Upon capture, fish were measured $(\mathrm{TL})(\mathrm{cm})$, weighed $(\mathrm{kg})$, and tagged with a $1.6 \mathrm{~cm}$ T-bar anchor tags (Floy Tag \& Mfg., Inc., model FD-94). Tags were individually numbered and colored coded, along with a phone number to report recaptures. Tags were inserted into the dorsal musculature between the second and third dorsal spines. Tagged fish were released as close to capture location as possible. The GPS coordinates of the capture and release locations were recorded for all tagged fish and traps. Soak times were also recorded for each trap. Individuals that were recaptured during our initial tagging effort were re-measured and released.

\subsection{Public awareness and reward program}

Reporting of recaptured fish was obtained through the establishment of a public awareness program. Potential fishers and fish processors were notified of the study at local meetings, workshops, and via public flyers. We assembled fishers for a public workshop where we demonstrated the necessary protocols and techniques for recording data specific to recaptures. We demonstrated techniques for accurately recording data and emphasized how this information could be utilized via such tools as GIS to inform critical information gaps. Each fisher was given a measuring board and data sheets for recording recapture data specific to location of recapture (GPS coordinates), depth, time and date of recapture, tag\# and color, fish length (TL), weight of fish, gear type, and total trip poundage. A reward of $\$ 35.00$ was offered for legal sized fish and their associated data and a reward of $\$ 10.00$ was offered for data from sub-legal sized recaptures or legal sized recaptures captured outside of season. Legal sized fish captured within season were re-measured and dissected to determine the sex of the individual.

\subsection{Translocation and homing}

Forty-one fish were randomly chosen and translocated to a new area in the vicinity of Point Estero, at distances ranging from 1.5 to $6.5 \mathrm{~km}$. Twenty-one fish were caught and translocated to point A (Fig. 1b) on 16 October 2004 ( $\sim 12 \mathrm{~m}$ depth), an area characterized by patchy rocky reef similar to where individuals were initially captured. Twenty fish were translocated to point B (Fig. 1b) on 15 December 2004 ( $15 \mathrm{~m}$ depth), with this area characterized by sandy bottom habitat, surrounded by patchy rock reef. These translocation areas were chosen because of their central location within the study area, their relatively far distance from the northern sampling range, and their differing substrate types. An individual was considered to successfully home if it was recaptured less than or equal to the mean site fidelity distance of all recaptures that were not translocated. The distance between the initial capture and recapture location for translocated individuals is hereafter referred to as the proximity distance.

\subsection{Analysis}

All statistical analyses were tested at a significance level of $\alpha=0.05$ using tests within either Minitab 16 (Minitab Inc.) or Sigmaplot 11 (Systat Software, Inc.). Comparisons of initial and recapture lengths of females and males were conducted using a Kruskall-Wallis ANOVA on Ranks test. A Pearson correlation test was used to test the relationship between the initial capture and recapture depth of individuals. A two-sample $T$-test was used to compare the initial capture depths between males and females.

The GPS coordinates of the initial capture and recapture locations of each individual were plotted within ArcGIS 9.3.1 (ESRI) as point shapefiles and analyzed to determine site fidelity, home range, and homing behavior. For general descriptive statistics of site fidelity (distance between the initial capture and recapture locations), the values of all 279 recapture events were used. To provide equal representation across all individuals, only site fidelity values from the 1 st recapture event of each individual was used $(n=245)$ for the following comparative analysis. A Mann-Whitney rank sum test was used to make comparisons of site fidelity between males and females. A Kruskall-Wallis ANOVA on Ranks test used to make comparisons of site fidelity recorded during spawning (October-March) vs. non-spawning periods (April-September) for males and females. A Kruskall-Wallis ANOVA on Ranks test was used to test for differences in all site fidelity values between initial fish length group bins (29.1-35.0, 35.1-40.0, 40.1-45.0, $45.1-50.0 \mathrm{~cm})$ and recapture depth group bins (0.0-5.0, 5.1-10.0, $10.1-15 \mathrm{~m})$.

For individuals with at least two recapture events, home range estimates were calculated using the minimum convex polygon (MCP) method (Fig. 3). Home range estimates were $\log _{10}$ transformed for the following analysis. To determine the effect of the number of recapture events on home range size, home ranges were compared between individuals experiencing 2 recapture events and individuals experiencing 3 or more recapture events using a two-sample $T$-test. Home ranges of males and females were compared using a one-way ANOVA test. Regression analysis was used 


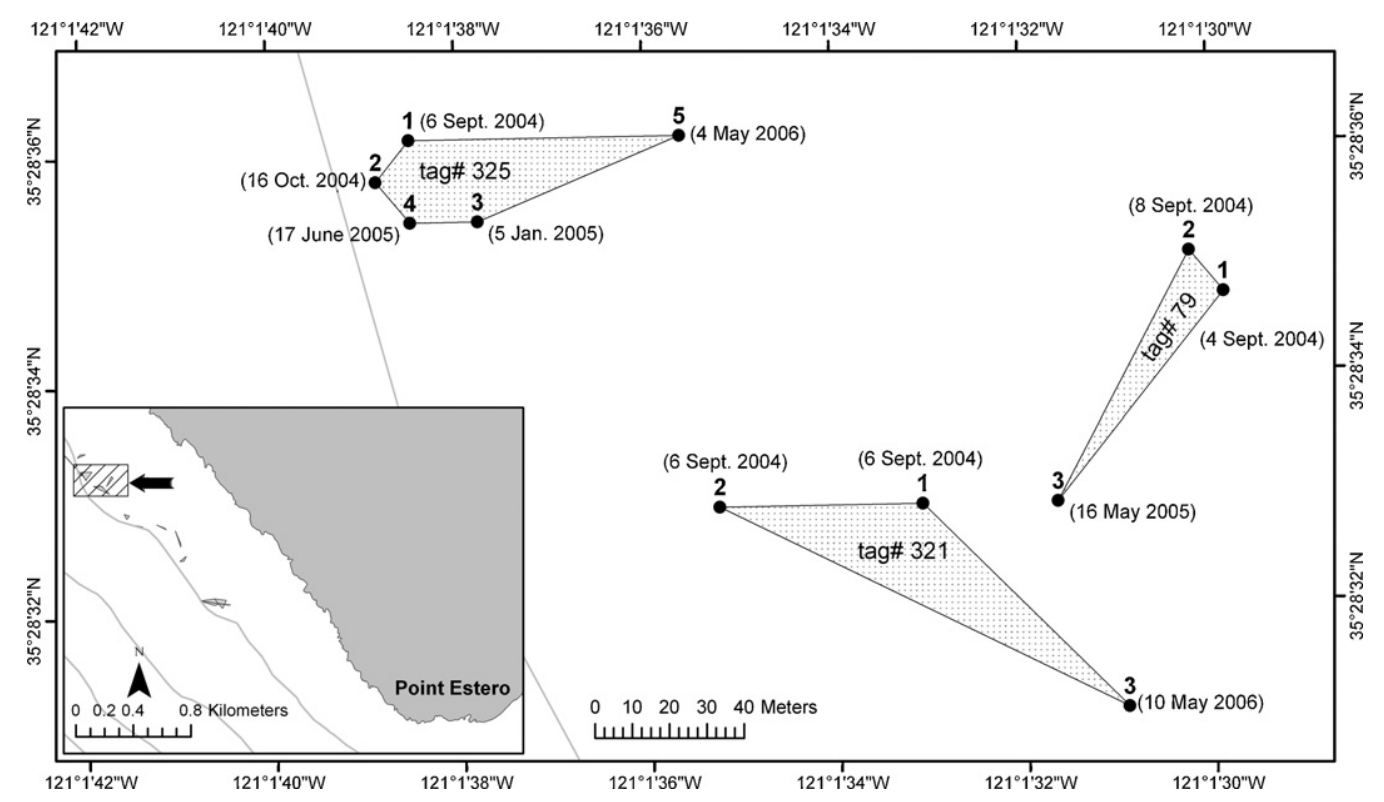

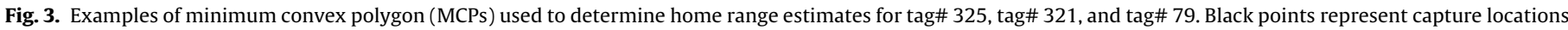
by date of occurrence, with " 1 " representing initial capture locations and subsequent numbers representing recaptures. Bathymetry lines represent $10 \mathrm{~m}$ isobaths.

to determine the relationship between home range size with initial capture length and total days at liberty (total number of days between initial and last recapture event).

To analyze homing behavior, the distances between the initial capture, translocation area, and recapture location for all translocated individuals were determined using ArcGIS. Individuals were considered to successfully home if their proximity distance was less than or equal to the mean site fidelity distance of non-translocated individuals. Regression analysis was used to analyze the relationship between the proximity distance with translocation distance, initial capture length of individuals, and days at liberty.

\section{Results}

\subsection{Catch statistics}

A total of 1240 individuals were captured over 10 days of fishing, with a mean $( \pm$ SD) of $124( \pm 31.1)$ individuals tagged per day. Most individuals (80\%) were captured between 4.5 and $12.5 \mathrm{~m}$ depth. During the initial tagging effort, captured individuals ranged in size from 24.5 to $56.0 \mathrm{~cm}$ TL with a mean length $( \pm S D)$ of $38.30 \mathrm{~cm}$ $( \pm 4.41)$. As of 15 June 2007, commercial fishers reported the recapture of 290 different individuals (23\% recapture rate), with 34 individuals experiencing multiple recapture events resulting in 330 total recaptures. Thirty-four fish were recaptured at least twice, five were recaptured three times, and one individual (tag\# 325) experienced 4 recapture events over a 605 day period (Fig. 3). From reported recaptures, dependable GPS coordinates were supplied for 279 recapture events from 245 different individuals, with 27 of these individuals recaptured multiple times. The recapture lengths for all 279 recapture events ranged in size from 29.9 to $50.0 \mathrm{~cm}$ with a mean length $( \pm$ SD) of $39.6( \pm 38.7) \mathrm{cm}$.

The time at liberty for recaptured individuals during all 279 recapture events ranged from $98 \mathrm{~min}$ to 1000 days, with individuals at liberty a mean $( \pm$ SD) of $273 \pm 209.7$ days. Six individuals were recaptured on the same day that they were initially tagged, after experiencing times at liberty ranging from 98 to $356 \mathrm{~min}$. Sex ratios for recaptured individuals that were at least the minimum size limit for retention ( $38 \mathrm{~cm}$ ), were $67 \%$ females $(n=127)$ to $33 \%$ males $(n=62)$, with females displaying significantly larger initial capture lengths (TL) than males (Kruskal-Wallis, $H=19.88, d f=1$, $p=0.001$ ) (Fig. 4a), as well as larger recapture lengths than males $(H=41.66, d f=1, p=0.001)$ (Fig. $4 \mathrm{~b})$.

There was a positive correlation between the initial capture depth and 1st recapture depth of individuals (Pearson's correlation, $r=0.60, p=0.00$ ) (Fig. 5a), as well as between the initial capture depth and the 2 nd recapture depth for individuals experiencing

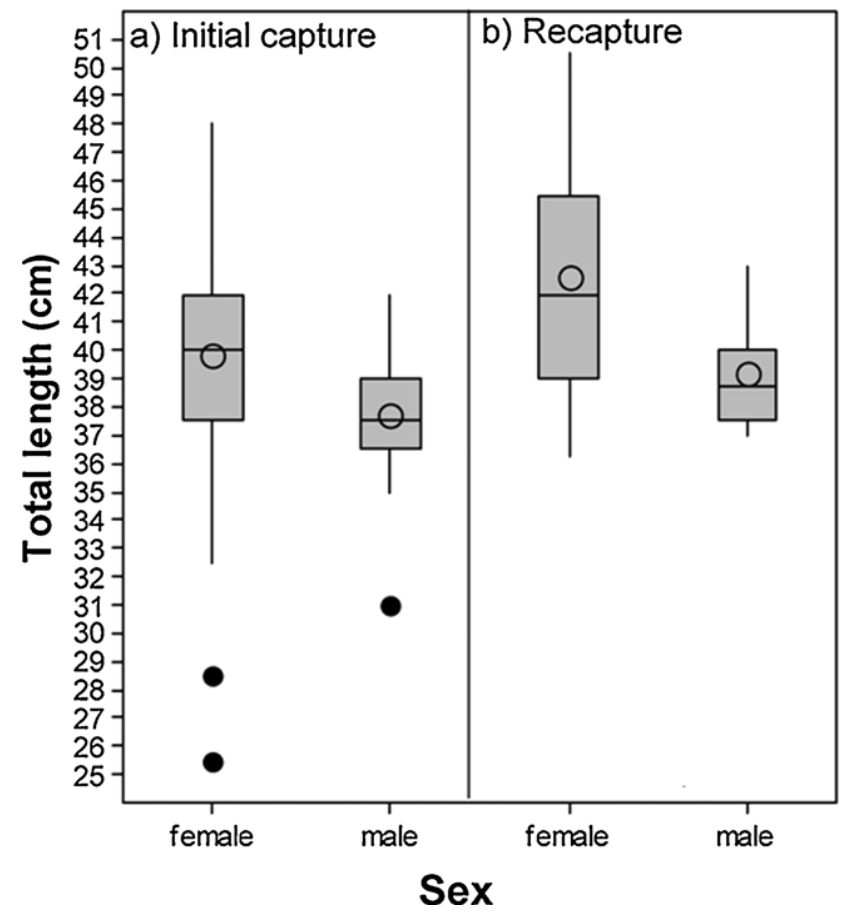

Fig. 4. Boxplots displaying the significant differences in total length $(\mathrm{cm})$ between females and males measured during the (a) initial capture (Kruskall-Wallis, $H=19.88, d f=1, p=0.001)$ and $(b)$ recapture events $(H=41.66, d f=1, p=0.001)$. Boxes represent the upper and lower limits of the interquartile range (middle 50\%) of data points, with the line within the box indicating the median, and open circles representing the mean. Whiskers extend a maximum of 1.5 box-lengths to minimum and maximum data points in the upper and lower $25 \%$ of the data. Solid black points represent outliers. 


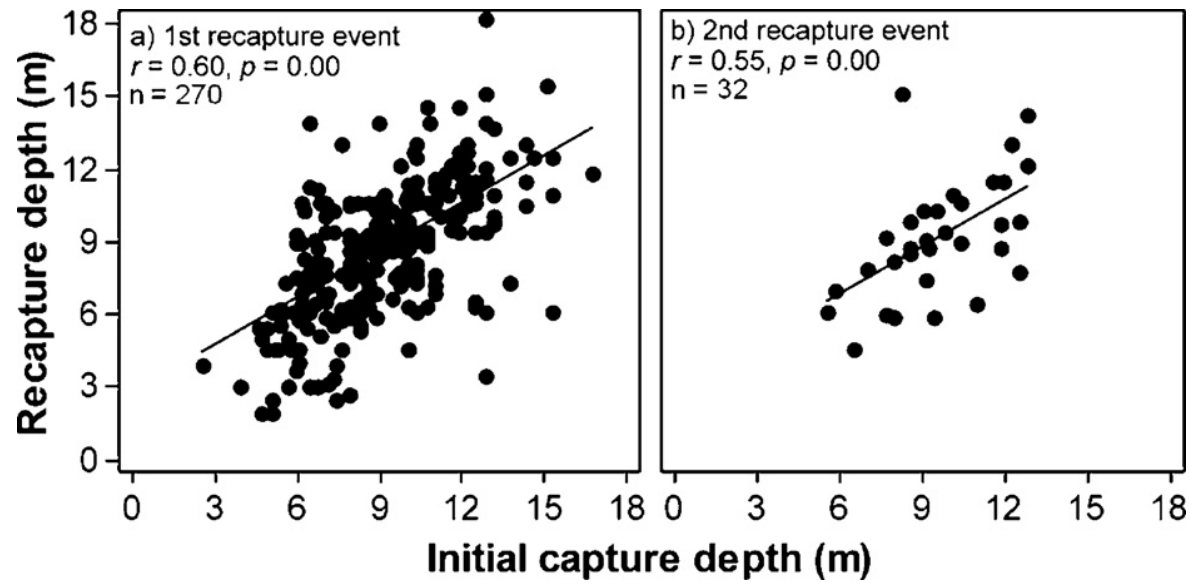

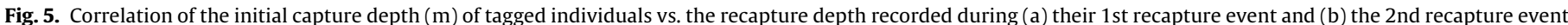
of 32 individuals that were recaptured multiple times.

multiple recaptures $(r=0.55, p=0.00)$ (Fig. $5 b)$. There was not a significant difference in the initial capture depths between males and females (two-sample $T$-test, $T=1.55, d f=533, p=0.12$ ).

\subsection{Site fidelity}

The mean $( \pm S D)$ site fidelity distance for all 279 recapture events was $210.7 \pm 811.0 \mathrm{~m}$ (Fig. 6 ). Only $5 \%$ of recaptures occurred greater than $500 \mathrm{~m}$ from their initial capture location (660; 766; 883; 941; $1397 ; 1581 ; 2201 ; 3037 ; 3538 ; 5028 ; 6057 ; 6545$; and $7410 \mathrm{~m}$ ) (Fig. 6). There was not a significant difference in site fidelity distance between male and females (Mann-Whitney, $T=3365.000$, $d f=1, p=0.131$ ), although it should be noted that seven of the nine recapture events that exceeded $1000 \mathrm{~m}$ were conducted by females, with only one male displaying a recapture distance of similar magnitude $(6057 \mathrm{~m})$ (Fig. 7). In comparisons of the site fidelity between spawning (October-March) and non-spawning (April-September) periods, there was not a significant difference for females (Kruskall-Wallis, $H=0.02, d f=1, p=0.877$ ) or males $(H=0.97, d f=1, p=0.326)$. There was not a significant difference in site fidelity between the four initial capture length $(\mathrm{cm})$ groups $(H=6.37, d f=3, p=0.095)$ or the three recapture depth groups $(H=0.94, d f=2, p=0.625)$. The two individuals at liberty the longest in this study (1000 days) were recaptured 21 and $14 \mathrm{~m}$ from their initial tagging location (Fig. 7).

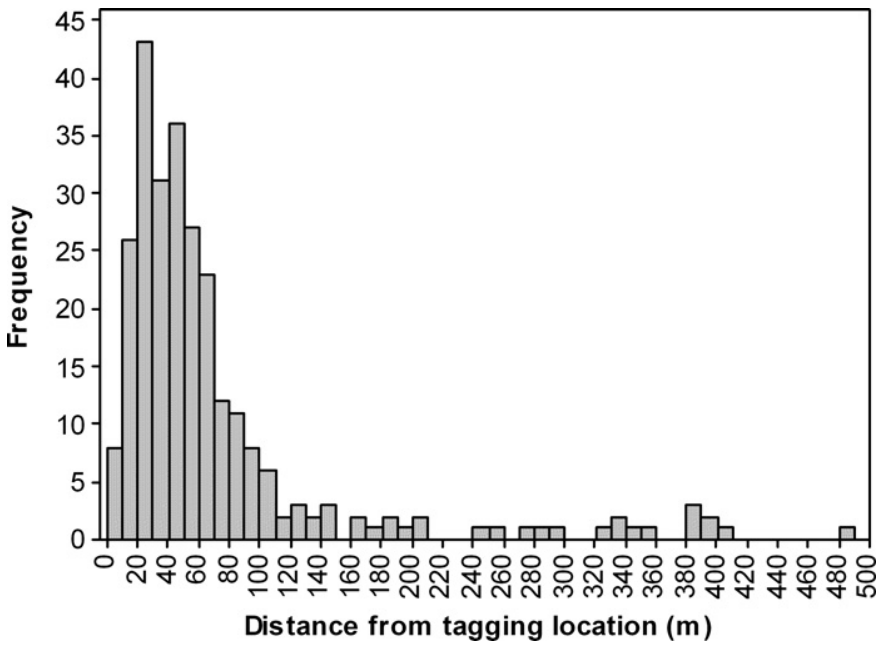

Fig. 6. Frequency of individuals recaptured varying distances from their initial capture location (total $n=279$ ). Only recaptures ranging from 0 to $500 \mathrm{~m}$ ( $95 \%$ of all recaptures) are presented. Other recaptures $>500 \mathrm{~m}$ are discussed in text.

\subsection{Home range}

Home range estimates were determined for a total of 27 different fish ranging in initial tagging size from 31.0 to $47.0 \mathrm{~cm}$ (TL), with an overall mean $( \pm \mathrm{SD})$ length of $36.8 \pm 3.66 \mathrm{~cm}$ (Table 1$)$. Home

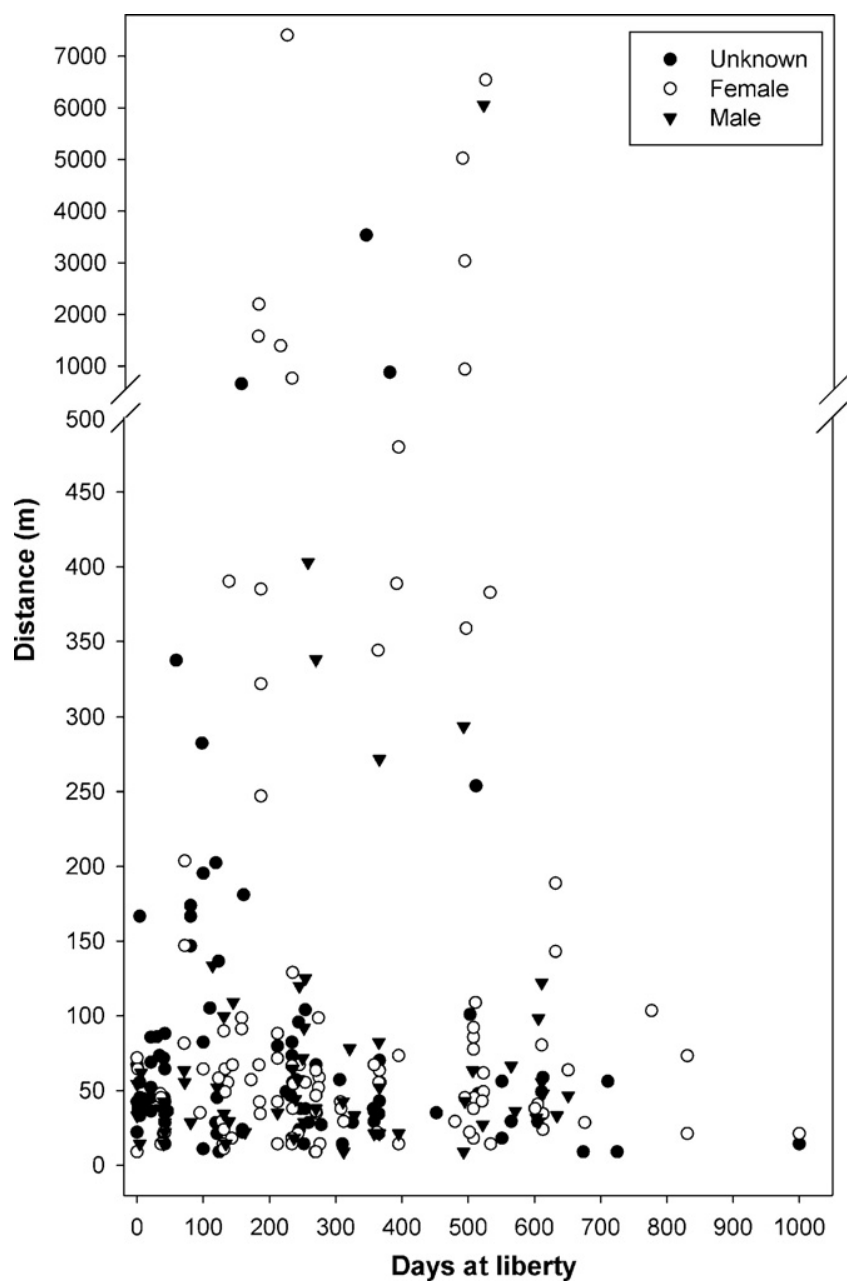

Fig. 7. Scatterplot of the distances that all 279 recapture events occurred from their initial capture locations by days at liberty since initial tagging. Female individuals are represented by open circles, males are represented by closed inverted triangles, and individuals whose sex was not determined are represented by closed circles. Note that the post break $(500 \mathrm{~m}) y$-axis tick interval is adjusted to $1000 \mathrm{~m}$. 
Table 1

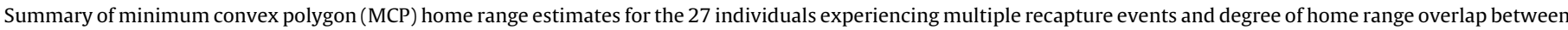
individuals. A (-) indicates data were not recorded.

\begin{tabular}{|c|c|c|c|c|c|c|c|}
\hline Tag\# & Sex & $\begin{array}{l}\text { Initial length } \\
(\mathrm{cm})\end{array}$ & $\begin{array}{l}\text { Last recapture } \\
\text { length }(\mathrm{cm})\end{array}$ & $\begin{array}{l}\text { Home } \\
\text { range }\left(\mathrm{m}^{2}\right)\end{array}$ & $\begin{array}{l}\text { Total days at } \\
\text { liberty }\end{array}$ & $\begin{array}{l}\text { Overlapping home ranges } \\
(\text { Tag\#(s)) }\end{array}$ & $\begin{array}{l}\text { Area }\left(\mathrm{m}^{2}\right) \text { of home range } \\
\text { overlap }\end{array}$ \\
\hline a 169 & - & 34.5 & 35 & 65000 & 42 & - & - \\
\hline${ }^{\mathrm{a}} 290$ & - & 35 & 36.5 & 0 & 240 & - & - \\
\hline 10 & - & 31 & 34.9 & 453 & 247 & - & - \\
\hline 20 & Male & 40 & 42 & 403 & 613 & - & - \\
\hline 25 & - & 40 & 42 & 151 & 42 & - & - \\
\hline 43 & - & 38 & 39.5 & 3524 & 102 & - & - \\
\hline 79 & Male & 39 & 40 & 504 & 254 & - & - \\
\hline 108 & - & 36 & 36.5 & 201 & 240 & - & \\
\hline 122 & Male & 31.5 & 37.5 & 201 & 653 & - & - \\
\hline 157 & Male & 36 & 38 & 403 & 312 & - & - \\
\hline 158 & Female & 39 & 40.5 & 1510 & 674 & - & - \\
\hline 263 & - & 36 & 37.5 & 1006 & 673 & - & - \\
\hline 281 & Female & 34.5 & 36.3 & 755 & 674 & - & - \\
\hline 303 & - & 37 & 37.5 & 3021 & 134 & $597 / 727$ & $67 / 162$ \\
\hline 310 & Female & 47 & 49 & 101 & 243 & - & - \\
\hline 321 & - & 35 & 37.5 & 1510 & 611 & & - \\
\hline 325 & - & 36.5 & 36.2 & 1107 & 605 & $327 / 1043$ & $885 / 117$ \\
\hline 327 & Female & 36 & 37 & 2014 & 611 & 325 & 885 \\
\hline 354 & Male & 42 & 43 & 2114 & 507 & - & - \\
\hline 407 & - & 42 & 41.9 & 504 & 121 & - & - \\
\hline 447 & Female & 36 & 37.5 & 302 & 364 & - & - \\
\hline 597 & - & 34.5 & 36.2 & 151 & 243 & $303 / 727$ & $67 / 46$ \\
\hline 727 & - & 34.5 & 36.2 & 2417 & 264 & $303 / 597$ & $162 / 46$ \\
\hline 910 & - & 34 & - & 805 & - & - & - \\
\hline 928 & - & 31.5 & 37 & 403 & 854 & - & - \\
\hline 1043 & Male & 35 & 39.5 & 151 & 611 & 325 & 117 \\
\hline 1109 & Female & 42 & 43.8 & 302 & 36 & - & - \\
\hline
\end{tabular}

a Not used in home range analysis.

range estimates ranged from 0 to $65,171 \mathrm{~m}^{2}$, with a mean $( \pm \mathrm{SD})$ of $3297 \pm 12368 \mathrm{~m}^{2}$ (Table 1 ). The minimum and maximum home range values were determined to be extreme outliers and were excluded from the following analysis in order to meet assumptions of normality necessary for analysis. The remaining 25 estimates ranged from 101 to $3524 \mathrm{~m}^{2}$ (mean $( \pm S D)=960 \pm 966 \mathrm{~m}^{2}$, median $=503 \mathrm{~m}^{2}$ ) (Fig. 8). Five individuals displayed overlapping home ranges with a mean $( \pm S D)$ overlap area of $255 \pm 355 \mathrm{~m}^{2}$. There was no significant difference in $\log _{10}$ home range estimates between individuals experiencing 2 recapture events and individuals experiencing 3 or more recapture events (two-sample $T$-test $T=1.67, d f=24, p=0.107)$. There was no relationship between initial capture length and home range $\left(\mathrm{m}^{2}\right)$ size (regression, $F=0.21, d f=1$,

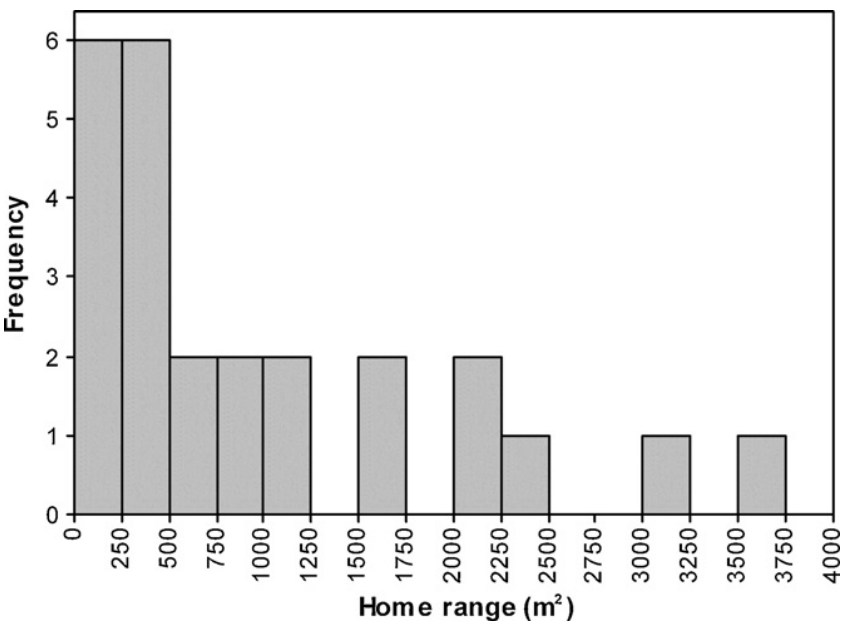

Fig. 8. Home range $\left(\mathrm{m}^{2}\right)$ frequencies of the 25 individuals that experienced at least 2 recapture events necessary for determining home range estimates. Home range estimates of $0.0 \mathrm{~m}^{2}$ (tag\# 290) and 65,171.2 $\mathrm{m}^{2}$ (tag\# 169) are not included. $p=0.67)$. There was no difference in home range estimates between males and females (ANOVA, $d f=1, F=0.06, p=0.81$ ), nor between the home ranges of sub-adult $(<38 \mathrm{~cm})$ and adult $(\geq 38 \mathrm{~cm})$ individuals $(F=0.61, d f=1, p=0.45)$. No relationship was found between home range size and total days a liberty (regression, $F=0.13, d f=1$, $p=0.72$ ).

\subsection{Homing behavior}

Ten individuals (24\%) out of the 41 total translocated individuals were recaptured, with all ten successfully homing to within $166 \mathrm{~m}$ of their initial capture location, after being translocated distances of up to $5.3 \mathrm{~km}$, with a mean $( \pm$ SD) translocation distance of $3.5 \pm 1.2 \mathrm{~km}$ (Fig. 9). The days at liberty for translocated recaptured individuals ranged from 21 to 328 days (mean $( \pm \mathrm{SD})=142.0 \pm 108.5$ days) (Table 2$)$. The proximity distance of recaptured individuals ranged from 14.3 to $166.7 \mathrm{~m}$, with a mean $( \pm$ SD) distance of $53.0 \pm 44.0 \mathrm{~m}$ (Table 2 ). Within 21 days of being translocated $4.3 \mathrm{~km}$, tag\# 1233 was recaptured within $52.1 \mathrm{~m}$ of its initial tagging location, and represents the shortest duration of time for a successful homing event (Table 2). The two individuals experiencing the furthest translocation distance $(5.3 \mathrm{~km})$ were recaptured within $36.3 \mathrm{~m}$ (tag\# 1021) and $33.3 \mathrm{~m}$ (tag\# 1023) of their initial tagging location after being at liberty 328 and 270 days, respectively (Table 2). Tag\# 1021 also represents the individual which was at liberty the longest (328 days) after displacement (Table 2). Only one translocated individual was recaptured greater than $100 \mathrm{~m}$ from its initial capture location, with all of the other 9 individuals recaptured within $73.5 \mathrm{~m}$ from their initial capture location. The proximity distance of recaptured individuals to their initial capture location was not found to be related to the translocation distance (regression, $F=1.65, d f=1, p=0.235$ ), initial capture length $(F=0.60, d f=1, p=0.461)$, or days at liberty between translocation and recapture events $(F=1.1, d f=1, p=0.324)$. 


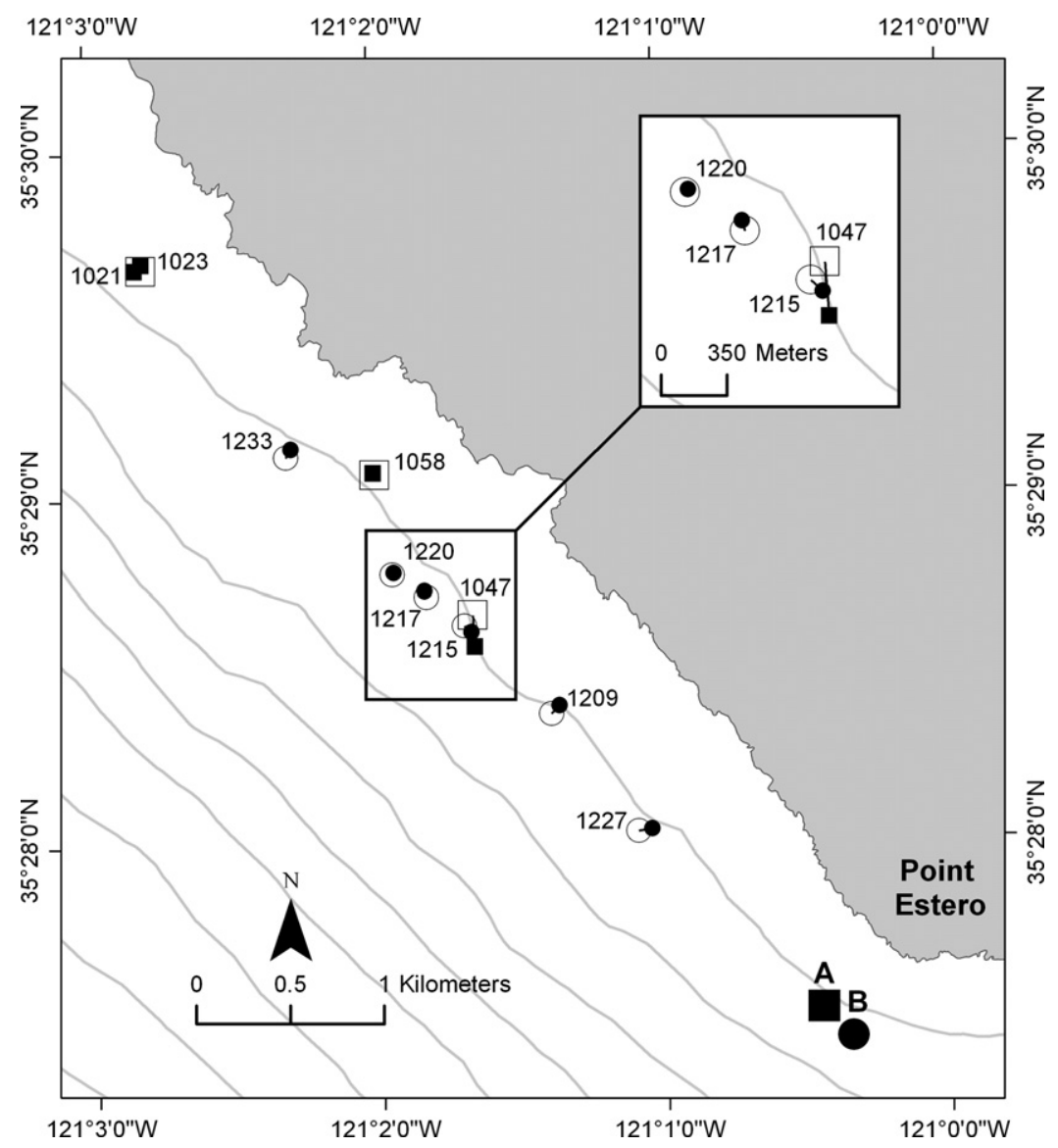

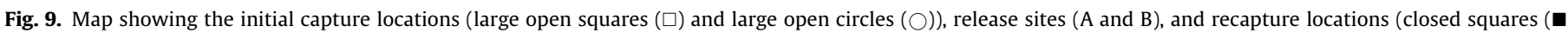

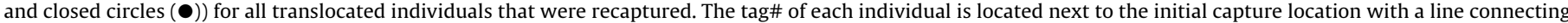

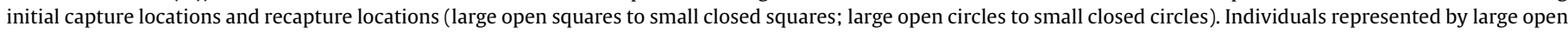

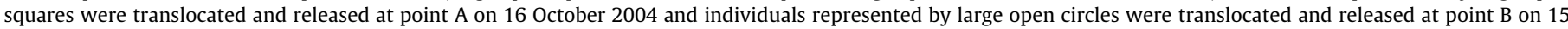
December 2004. Bathymetry lines represent $10 \mathrm{~m}$ isobaths.

\section{Discussion}

\subsection{Catch statistics}

The assistance of local commercial fishers in the tagging and recapturing of individuals, proved to be an important aspect to this study, resulting in an overall high recapture rate. The number of individuals exhibiting multiple recaptures was unexpected, especially considering that tag\# 325 was recaptured on 4 separate occasions over 605 days. Effects of tagging induced stress on behavior appear to be limited, since 6 individuals were recaptured on the same day that they were tagged, with one individual at liberty for only $98 \mathrm{~min}$. The positive correlation between initial capture depth and recapture depth(s) indicate that individuals exhibit tendencies to occupy similar depths over time. In California, males and females have been observed to reach lengths of at least 55.9 and $72.0 \mathrm{~cm}$, respectively (O'Connell, 1953); however, findings in this study are only representative of individuals ranging in size from 17.5 to $56.0 \mathrm{~cm}$. During the initial tagging effort, larger fish were likely prevented from being captured by the "sea otter exclusion rings" present on the posterior portion of the funnel leading into the traps. We found females to display significantly longer initial and recapture lengths than males, which is supported by previous studies demonstrating females to obtain larger sizes than males (O'Connell, 1953; Grebel and Cailliet, 2010). Females comprised a majority of the individuals recaptured in this study, suggesting that males may not be as abundant in the area. Since a portion of tagging was completed during the reported spawning period for cabezon

Table 2

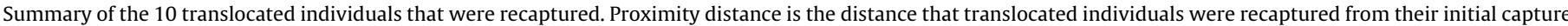
location. A (-) indicates that sex was not recorded.

\begin{tabular}{|c|c|c|c|c|c|c|c|c|c|}
\hline Tag\# & $\begin{array}{l}\text { Translocation } \\
\text { distance }(\mathrm{km})\end{array}$ & $\begin{array}{l}\text { Return distance } \\
(\mathrm{km})\end{array}$ & $\begin{array}{l}\text { Proximity } \\
\text { distance }(\mathrm{m})\end{array}$ & $\begin{array}{l}\text { Initial capture/translocation } \\
\text { date (dd-mmm-yy) }\end{array}$ & $\begin{array}{l}\text { Recapture } \\
\text { date }\end{array}$ & $\begin{array}{l}\text { Days at } \\
\text { liberty }\end{array}$ & $\begin{array}{l}\text { Initial length } \\
(\mathrm{cm})\end{array}$ & $\begin{array}{l}\text { Recapture } \\
\text { length }(\mathrm{cm})\end{array}$ & Sex \\
\hline 1215 & 3 & 3 & 49.3 & 15-Dec-04 & 18-Jun-05 & 185 & 45 & 47.5 & Female \\
\hline 1217 & 3.3 & 3.3 & 34.5 & 15-Dec-04 & 19-Jun-05 & 186 & 39.5 & 41.5 & Female \\
\hline 1220 & 3.5 & 3.5 & 14.3 & 15-Dec-04 & 20-Jan-05 & 36 & 38 & 40.6 & Female \\
\hline 1058 & 3.7 & 3.7 & 14.3 & 16-Oct-04 & 16-May-05 & 212 & 41 & 42.5 & Female \\
\hline 1023 & 5.3 & 5.4 & 33.3 & $16-O c t-04$ & 13-Jul-05 & 270 & 46.5 & 47.5 & Female \\
\hline 1209 & 2.4 & 2.4 & 63.5 & 15-Dec-04 & 24-Feb-05 & 71 & 37.5 & 38.7 & Male \\
\hline 1021 & 5.3 & 5.4 & 36.3 & $16-O c t-04$ & 9-Sep-05 & 328 & 36 & 37 & Male \\
\hline 1227 & 1.6 & 1.5 & 73.5 & 15-Dec-04 & 18-Jan-05 & 34 & 35.5 & 36.8 & - \\
\hline 1047 & 2.8 & 2.7 & 166.7 & 16-Oct-04 & 5-Jan-05 & 81 & 45 & 45.1 & - \\
\hline 1233 & 4.3 & 4.3 & 52.1 & 15-Dec-04 & 5-Jan-05 & 21 & 38 & 39.4 & - \\
\hline
\end{tabular}


(October-March (O'Connell, 1953)), and males have been reported to remain at nesting sites for up to 131 days (Lauth, MSc Thesis, 1987), it is also possible that larger males guarding nests were less likely to leave nest areas to forage, and therefore less likely to be captured and tagged.

\subsection{Site fidelity}

Findings demonstrate that a majority of cabezon individuals (81\%) displayed site fidelity to within $100 \mathrm{~m}$ of their initial capture location, with more than half of all recaptures (52\%) displaying fidelity to within $50 \mathrm{~m}$. After 1000 days at liberty, two individuals were recaptured 21 and $14 \mathrm{~m}$ from their initial capture locations, showing that individuals can display site fidelity to a specific area over prolonged periods of time. Other studies have also found cabezon to display high site fidelity to specific areas. In a previous tagging study in central California, 3 recaptured cabezon were not found to exhibit movement away from their initial tagging location (Lea et al., 1999). In Southern California, acoustically tagged cabezon remained at oil platforms for up to 560 days in the Santa Barbara Channel (Lowe et al., 2009) and at least 555 days on platforms on the San Pedro Shelf (Mireles, MSc Thesis, 2010). During diver surveys, male cabezon have been observed to utilize the same nesting sites during consecutive years (Lauth, MSc Thesis, 1987). Many species within the family Cottidae have also been reported to display strong site fidelity over extended periods of time to specific home areas, including tidepool sculpin (Green, 1971; Khoo, 1974), woolly sculpin (Williams, 1957), fluffy sculpin (Oligocottus snyderi), and mosshead sculpin (Clinocottus globiceps) (Yoshiyama et al., 1992).

While a majority of cabezon exhibited high site fidelity, results also indicate that cabezon are capable of displaying movements of greater magnitude, given that 13 of the 279 recapture events occurred greater than $500 \mathrm{~m}$ from their initial capture location. Male nest guarding behavior may explain why 7 of 9 recaptures occurring $>1000 \mathrm{~m}$ from initial capture locations were exhibited by females, although no overall difference in site fidelity was found between males and females. Similarly, we did not find a spawning season effect on site fidelity for males and females, so it is possible that most individuals utilize the same small areas across seasons for sheltering, foraging, and spawning activities.

\subsection{Home range}

The results of this study provide the first estimates of cabezon home range and further indicate that cabezon confine their activities to relatively small areas (mean $( \pm S D)=960 \pm 966 \mathrm{~m}^{2}$ ), based on individuals that experienced between 2 and 4 recapture events. The MCP analysis used to determine home range estimates is especially sensitive to the number of recapture events (locations) (Hooge et al., 2001) and in order to proceed with comparative analysis, it was important to determine whether the number of recapture events experienced by individuals influenced home range estimates. Given that we did not find a significant difference in home range estimates between individuals experiencing a varying number of recapture events, all home range estimates were pooled for comparative analysis.

Findings of this study are consistent with home range estimates for other similarly sized demersal reef fish. In previous acoustic tagging studies, copper rockfish (Sebastes caurinus) displayed home ranges less than $4000 \mathrm{~m}^{2}$ (Matthews, 1990), while lingcod (Ophiodon elongatus), copper rockfish, and quillback rockfish (Sebastes maliger) all exhibited home ranges between 1500 and $2500 \mathrm{~m}^{2}$ (Tolimieri et al., 2009). Checkered snapper (Lutjanus decussates) was also found to display similar small home range sizes as cabezon, ranging from 93 to $3638 \mathrm{~m}^{2}$ (Nanami and Yamada, 2008).
Considering that during reproductive periods male cabezon have been reported to aggressively guard nesting sites and remain at specific sites for prolonged periods of time (Lauth, MSc Thesis, 1987), individuals may be adapted to foraging and sheltering in small specific home areas.

Previous studies have found the home ranges of fishes to be related to feeding (Larson, 1980; Lowry and Suthers, 2004; Lowe et al., 2003; Topping et al., 2005), fish size (Larson, 1980), and sheltering activities (Larson, 1980; Topping et al., 2005; Bellquist et al., 2008). Studies using acoustic telemetry to investigate the fine scale movements of temperate reef fishes have found some species to forage and shelter in different locations (ex. shelter in reef, feed over sand) (Topping et al., 2005; Bellquist et al., 2008; Mason and Lowe, 2010) resulting in much larger home ranges than those observed for cabezon, which display a high affinity for reef habitat. Since we did not find a significant relationship between home range estimates and fish size, sex, capture depth, or days at liberty, other factors related to the extent or type of available habitat (Matthews, 1990; Eristhee and Oxenford, 2001; Topping et al., 2005; Mason and Lowe, 2010) may better explain cabezon home range. Copper rockfish inhabiting high relief reef habitat, displayed smaller home ranges $\left(\sim 5 \mathrm{~m}^{2}\right)$ than individuals at low relief reef $\left(\sim 4000 \mathrm{~m}^{2}\right)$, suggesting that areas with higher relief may provide better habitat for highly demersal reef species such as cabezon (Matthews, 1990). The home range sizes of gopher rockfish and black and yellow rockfish, which occupy similar benthic habitats as cabezon, have also been reported to be heavily influenced by habitat topography (Larson, 1980). Although we were unable to characterize the extent of available habitat in our study area, the distribution of tagged fish in our initial tagging effort suggests that suitable reef habitat is available throughout most of the $18 \mathrm{~km}$ of the study range. Despite the presence of suitable habitat throughout the area, most individuals appear to limit their home ranges to a particular site. This is further supported by the fact that recaptured translocated individuals returned to their initial capture location after likely encountering suitable habitat within close distance of the areas they were translocated to.

The home ranges of five individuals overlap, suggesting that some individuals use common areas. Acoustic telemetry studies recording the fine scale movements of multiple individuals have reported the home ranges of snapper (Pagrus auratus) (Parsons et al., 2003), blue rockfish (Sebastes mystinus) (Jorgensen et al., 2006), and Bermuda chub (Kyphosus sectatrix) (Eristhee and Oxenford, 2001) to overlap considerably. For cabezon the mean area of home range overlap was much lower than the mean home range estimate, suggesting that the areas shared by individuals could be limited. Since we do not know the locations of cabezon between capture events, it is unclear to what degree individuals occupy common areas.

\subsection{Homing}

After experiencing translocation distances up to $5.3 \mathrm{~km}$, all ten recaptured translocated individuals successfully returned to within close proximity (14.3-166.7 m) of their initial capture location. The recapture rate for translocated individuals (24\%) was similar to non-translocated individuals (23\%), demonstrating that cabezon exhibit strong homing behavior. The strong site fidelity of cabezon to a particular home area is further supported by findings that translocated individuals were recaptured as close to their initial capture location (mean distance $53 \mathrm{~m}$ ) as non-translocated individuals (mean distance $210 \mathrm{~m}$ ). The possibility that individuals were translocated to familiar locations within their general home ranges was a concern. While 1 non-translocated individual was recaptured $7 \mathrm{~km}$ from their initial capture location, most individuals (95\%) displayed site fidelity to within $500 \mathrm{~m}$ of their initial capture location, 
suggesting that the distances that individuals were translocated were appropriate to measure homing behavior.

Our findings are consistent with one report of a translocated cabezon individual to be recaptured away from the reef from where it was translocated to and in the direction of the initial capture location (Lea et al., 1999). Homing behavior has similarly been found for various species of rockfish (Sebastes spp.) (Carlson and Haight, 1972; Matthews, 1990; Mitamura et al., 2005; Anthony, MSc Thesis, 2009), Pacific halibut (Hippoglossus stenolepis) (Loher, 2008), lingcod (Matthews, 1992; Starr et al., 2004; Anthony, MSc Thesis, 2009), blacksmith (Chromis punctipinnis), and senorita (Oxyjulis californica) (Hartney, 1996). It has been proposed that fishes have developed homing abilities to return to familiar areas after moving to other areas to meet biological needs (ex. dietary, reproductive) or to possibly avoid unfavorable conditions (Gerking, 1959). Considering that juvenile through adult stages of cabezon are commonly found in the intertidal zone (O'Connell, 1953; Lauth, 1988), where there are constant fluctuations in temperature, wave stress, and water coverage (Williams, 1957), cabezon likely utilize homing behavior to safely navigate these areas. Although it is not known if cabezon at any life stage display fidelity to certain home pools within the intertidal, homing behavior to home pools has been well documented for other Cottids such as woolly sculpin (Williams, 1957), tidepool sculpin (Green, 1971; Khoo, 1974) and fluffy sculpin (Yoshiyama et al., 1992).

Olfaction may play a key role in the homing ability of cabezon, as it does in both tidepool sculpin (Khoo, 1974) and Japanese black rockfish (Sebastes inermis: Sebastidae) (Mitamura et al., 2005). Blinded fish allowed to use olfactory senses display homing abilities comparable to normal fish (Khoo, 1974; Mitamura et al., 2005), demonstrating that visual cues may not play as important of a role in homing behavior. If olfaction is in fact the primary tool used in the homing of cabezon, chemical environmental factors would play an important role in the ability of cabezon to home. Since all individuals were translocated from north to the south, which is same direction as the dominate current in the area, a future translocation study moving fish from south to north could lend evidence as to the influence of chemical cues on homing success.

The time needed for individuals to successfully home cannot be accurately determined in this study, since we only know when individuals were recaptured, not when they actually returned. After being at liberty for 21 days, tag\# 1233 was recaptured within $52.1 \mathrm{~m}$ of its initial capture location after being displaced $4.3 \mathrm{~km}$, making 21 days our best estimate for the least time needed to home. These estimates are similar to reports of quillback rockfish successfully homing within 8-25 days after being translocated $500 \mathrm{~m}$ (Matthews, 1990). Not only did translocated cabezon individuals return to their initial capture location, but they appeared to remain at these sites after their return. After 328 days of being translocated $5.3 \mathrm{~km}$, tag\# 1021, was recaptured within $36 \mathrm{~m}$ of its initial capture location. The possibility that this individual returned at an earlier date and remained at the site, or that the individual had returned on the date that it was recaptured, demonstrates the high site fidelity of cabezon for a particular site. Cottids may retain spatial familiarity with home areas for extended periods of time. After a 6-month confinement within a translocated pool, a tidepool sculpin was reported to successfully home to its original home pool (Green, 1971). The homing ability of tidepool sculpin displaced from home pools was not found to be influence by age (Green, 1971), possibly suggesting that homing is an innate behavior for Cottids.

\subsection{Future management and monitoring implications}

The results of this study demonstrate the potential effectiveness of collaborative investigations as well the potential for future monitoring programs. Utilizing the expertise of commercial fishers, we were able to tag 1240 individuals in 10 days of fishing, a task which would have been virtually impossible for us to do alone. In addition, if it was not for the participation of fishers in the reporting of recaptures (23\% recapture rate) it is likely that we would have not acquired sufficient data. Since the quality of data retrieved from fishers was extremely valuable to our investigation, we feel that future studies relying on recaptures from fishers should consider a comprehensive public awareness, training, and reward program. For fishers in our study, it was important that the monetary incentive to accurately record and report data from recaptures, as well as supply tagged individual to us, exceed the market value of that fish by US $\$ 10.00-20.00$. The continuous interaction with fishers also provided a platform for communication, which allowed for fishers to voice their concerns and provide their expert opinions on investigatory findings. This communication provided fishers with a better understanding of how data were being utilized to answer important scientific questions. With the MLPA for the entire coast of California projected to be completed in 2011, collaborative studies can provide an extremely valuable tool for future monitoring and assessment of MPAs (Wendt and Starr, 2009).

Findings demonstrate cabezon in the vicinity of Estero Reef to show high site fidelity to a specific home range for extended periods of time (at least 1000 days), which was further supported by their propensity to home back to initial capture locations after being translocated up to $5.3 \mathrm{~km}$. Considering these findings, density dependent spillover and movement from MPAs to surrounding unprotected areas may play a limited role in supplementing outside targeted populations, when compared to larval supply. A majority of individuals (81\%) were recaptured within $100 \mathrm{~m}$ of their initial capture locations, suggesting that sub-adult and adult spillover to surrounding fished areas will likely only be effective out to a distance of $100 \mathrm{~m}$ from protective boundaries. However, this will likely depend on the extent and connectedness of suitable habitat extending from inside protective areas to surrounding unprotected areas. Since natural barriers such as unfavorable habitat may also limit movement (Kramer and Chapman, 1999), managers should consider the role of habitat connectivity in post-settlement spillover. Given that larval supply will depend on the ability of MPAs to protect individuals, our home range results suggest that a majority of individuals (67\%) would require an area of $1000 \mathrm{~m}^{2}$ to be completely protected. To completely protect $96 \%$ of the individuals used in our home range estimates, the size of the area for each individual would need to be at least $3700 \mathrm{~m}^{2}$. These estimates, coupled with site specific biomass, size class frequency, and density data, can provide mangers with a proxy to estimate the size of the area needed to protect populations of specific sizes. The influence of habitat topography on site fidelity and home range should also be further assessed. Since our study was conducted in an area that was historically fished, factors of density dependent movement may not be as pronounced as in established MPAs. In 2007, during the implementation of the MLPA, a portion of our study area was converted to the White Rock State Marine Conservation Area. This area now provides an ideal setting for future comparative analysis to understand how factors of protection influence movement and site fidelity, which will be vital to the evaluation and assessment of MPAs as a fisheries conservation tool.

\section{Acknowledgements}

We thank the California Resources Legacy Fund for financial support, as well as the Marine Interest Group of San Luis Obispo County for fostering this collaboration. Cal Poly Biological Sciences Student Activities Fund also provided additional financial support. A special thanks to Tom Hafer, Roger Cullen, and their crews for providing their expertise and assistance throughout all aspects of the 
study. We are especially grateful to all the commercial fishers who reported recaptures, and Jimbo and Pam at Bayshore Fish Company for helping to report recaptures and provide flyers to fishers. This research would not have been possible without the assistance of Erin Nakada, Nate Hall, Leslie Longbaugh, Hilary Furnis-Lawrence, and Dave Rasmussen. We also thank Dr. Andrew Schaffner for help with statistical analysis, as well as David Yun, Jordan Gass, and Nicholas Hayden for assistance with ArcGIS analysis. We also thank the two anonymous reviewers whose comments and suggestions improved this manuscript significantly.

\section{References}

Abesamis, R.A., Russ, G.R., 2005. Density-dependent spillover from a marine reserve: long-term evidence. Ecol. Appl. 15, 1798-1812.

Afonso, P., Fontes, J., Holland, K.N., Santos, R.S., 2008. Social status determines behaviour and habitat usage in a temperate parrotfish: implications for marine reserve design. Mar. Ecol. Prog. Ser. 359, 215-227.

Bellquist, L.F., Lowe, C.G., Caselle, J.E., 2008. Fine-scale movement patterns, site fidelity, and habitat selection of ocean whitefish (Caulolatilus princeps). Fish. Res. 91, 325-335.

California Department of Fish and Game, 2008. California Marine Life Protection Act Master Plan for Marine Protected Areas. Appendix G.

Carlson, H.R., Haight, R.E., 1972. Evidence for a home site and homing of adult yellowtail rockfish Sebastes flavidus. Fish. Res. Bd. Can. 29, 1011-1014.

Cope, J.M., Punt, A.E., 2005. Status of Cabezon (Scorpaenichthys marmoratus) in California Waters as Assessed in 2005. Pacific Fishery Management Council, Portland, OR.

Ebeling, A.W., Bray, R.N., 1976. Day versus night activity of reef fishes in a kelp forest off Santa-Barbara, California. Fish. B-NOAA 74, 703-717.

Eristhee, N., Oxenford, H.A., 2001. Home range size and use of space by Bermuda chub Kyphosus sectatrix (L.) in two marine reserves in the Soufriere Marine Management Area, St Lucia, West Indies. J. Fish Biol. 59, 129-151.

Gaines, S.D., White, C., Carr, M.H., Palumbi, S.R., 2010. Designing marine reserve networks for both conservation and fisheries management. Proc. Natl. Acad. Sci. U.S.A. 107, 18286-18293.

Gell, F.R., Roberts, C.M., 2003. Benefits beyond boundaries: the fishery effects of marine reserves. Trends Ecol. Evol. 18, 448-455.

Gerking, S.D., 1959. The restricted movement of fish populations. Biol. Rev. 34, 221-242.

Grebel, J.M., Cailliet, G.M., 2010. Age, growth, and maturity of cabezon (Scorpaenichthys marmoratus) in California. Calif. Fish Game 96, 36-52.

Green, J.M., 1971. High tide movements and homing behaviour of tidepool sculpin Oligocottus maculosus. Fish Res. Bd. Can. 28, 383-389.

Hartney, K.B., 1996. Site fidelity and homing behaviour of some kelp-bed fishes. J. Fish Biol. 49, 1062-1069.

Hooge, P.N., Eichenlaub, W.M., Solomon, E.K., 2001. Using GIS to analyze animal movements in the marine environment. In: Kruse, G.H., Bez, N., Booth, A., Dorn, M.W., Hills, S., Lipcius, R.N., Pelletier, D., Roy, C., Smith, S.J., Witherell, D. (Eds.), Spatial Processes and Management of Marine Populations. University of Alaska Sea Grant College, Fairbanks, pp. 37-51.

Jorgensen, S.J., Kaplan, D.M., Klimley, A.P., Morgan, S.G., O’Farrell, M.R., Botsford, L.W., 2006. Limited movement in blue rockfish Sebastes mystinus: internal structure of home range. Mar. Ecol. Prog. Ser. 327, 157-170.

Kerwath, S.E., Gotz, A., Attwood, C.G., Sauer, W.H.H., Wilke, C.G., 2007. Area utilisation and activity patterns of roman Chrysoblephus laticeps (Sparidae) in a small marine protected area. Afr. J. Mar. Sci. 29, 259-270.

Khoo, H.W., 1974. Sensory basis of homing in intertidal fish Oligocottus maculosus Girard. Can. J. Zool. 52, 1023-1029.

Kramer, D.L., Chapman, M.R., 1999. Implications of fish home range size and relocation for marine reserve function. Environ. Biol. Fish. 55, 65-79.
Larson, R.J., 1980. Territorial behavior of the black and yellow rockfish and gopher rockfish (Scorpaenidae, Sebastes). Mar. Biol. 58, 111-122.

Lauth, R.R., 1988. Seasonal spawning cycle, spawning frequency, and batch fecundity of the cabezon, Scorpaenichthys marmoratus, in Puget Sound, Washington. Fish. B-NOAA 87, 145-154.

Lea, R.N., McAllister, R.D., VenTresca, D.A., 1999. Biological aspects of nearshore rockfishes of the genus Sebastes from central California with notes on ecological related sport fishes. Fish. Bull., 177.

Loher, T., 2008. Homing and summer feeding site fidelity of Pacific halibut (Hippoglossus stenolepis) in the Gulf of Alaska, established using satellitetransmitting archival tags. Fish. Res. 92, 63-69.

Lowe, C.G., Topping, D.T., Cartamil, D.P., Papastamatiou, Y.P., 2003. Movement patterns, home range, and habitat utilization of adult kelp bass Paralabrax clathratus in a temperate no-take marine reserve. Mar. Ecol. Prog. Ser. 256, 205-216.

Lowe, C.G., Anthony, K.M., Jarvis, E.T., Bellquist, L.F., Love, M.S., 2009. Site fidelity and movement patterns of groundfish associated with offshore petroleum platforms in the Santa Barbara Channel. Mar. Coast. Fish.: Dynam. Manage. Ecosyst. Sci. 1, 71-89.

Lowry, M., Suthers, I., 2004. Population structure of aggregations, and response to spear fishing, of a large temperate reef fish Cheilodactylus fuscus. Mar. Ecol. Prog. Ser. 273, 199-210.

Mason, T.J., Lowe, C.G., 2010. Home range, habitat use, and site fidelity of barred sand bass within a southern California marine protected area. Fish. Res. 106, 93-101.

Matthews, K.R., 1990. A telemetric study of the home ranges and homing routes of copper and quillback rockfishes on shallow rocky reefs. Can. J. Zool. 68, 2243-2250.

Matthews, K.R., 1992. A Telemetric study of the home ranges and homing routes of lingcod Ophiodon elongatus on shallow rocky reefs off Vancouver Island, BritishColumbia. Fish. B-NOAA 90, 784-790.

Miller, D.J., Lea, R.N., 1972. Guide to the coastal marine fishes of California. Calif. Fish Game Fish Bull., 157.

Mitamura, H., Arai, N., Sakamoto, W., Mitsunaga, Y., Tanaka, H., Mukai, Y., Nakamura, K., Sasaki, M., Yoneda, Y., 2005. Role of olfaction and vision in homing behaviour of black rockfish Sebastes inermis. J. Exp. Mar. Biol. Ecol. 322, 123-134.

Nanami, A., Yamada, H., 2008. Size and spatial arrangement of home range of checkered snapper Lutjanus decussatus (Lutjanidae) in an Okinawan coral reef determined using a portable GPS receiver. Mar. Biol. 153, 1103-1111.

O'Connell, C.P., 1953. The life history of the cabezon. Fish Bull., 93.

Parsons, D.M., Babcock, R.C., Hankin, R.K.S., Willis, T.J., Aitken, J.P., O’Dor, R.K. Jackson, G.D., 2003. Snapper Pagus auratus (Sparidae) home range dynamics: acoustic tagging studies in a marine reserve. Mar. Ecol. Prog. Ser. 262, 253-265.

Pomeroy, R., Parks, J., Pollnacc, R., Campsond, T., Genioe, E., Marlessyf, C., Holleg E., Pidoh, M., Nissapai, A., Boromthanarati, S., Thu Huej, N., 2007. Fish wars: conflict and collaboration in fisheries management in Southeast Asia. Mar. Pol 31, 645-656.

Roberts, C.M., Hawkins, J.P., Gell, F.R., 2005. The role of marine reserves in achieving sustainable fisheries. Philos. Trans. R. Soc. B: Biol. Sci. 360, 123-132.

Starr, R.M., O'Connell, V., Ralston, S., 2004. Movements of lingcod (Ophiodon elongatus) in southeast Alaska: potential for increased conservation and yield from marine reserves. Can. J. Fish. Aquat. Sci. 61, 1083-1094.

Tolimieri, N., Andrews, K., Williams, G., Katz, S., Levin, P.S., 2009. Home range size and patterns of space use by lingcod, copper rockfish and quillback rockfish in relation to diel and tidal cycles. Mar. Ecol. Prog. Ser. 380, 229-243.

Topping, D.T., Lowe, C.G., Caselle, J.E., 2005. Home range and habitat utilization of adult California sheephead, Semicossyphus pulcher (Labridae), in a temperate no-take marine reserve. Mar. Biol. 147, 301-311.

Wendt, D.E., Starr, R.M., 2009. Collaborative research: an effective way to collect data for stock assessments and evaluate marine protected areas in California. Mar. Coast. Fish.: Dynam. Manage. Ecosyst. Sci. 1, 315-324.

Williams, G., 1957. Homing behavior of California rocky shore fishes. Univ. Calif. Publ. Zool. 59, 249-284.

Wilson-Vandenburg, D., Hardy, R., 2001. Cabezon. In: California Marine Living Resources: A Status Report. Calif. Fish Game, Sacramento, CA, pp. 157-159.

Yoshiyama, R.M., Gaylord, K.B., Philippart, M.T., Moore, T.R., Jordan, J.R., Coon, C.C., Schalk, L.L., Valpey, C.J., Tosques, I., 1992. Homing behavior and site fidelity in intertidal sculpins (Pisces, Cottidae). J. Exp. Mar. Biol. Ecol. 160, 115-130. 